\title{
HISTÓRIA, CULTURA E MEMÓRIA: A LITERATURA DE NÍSIA FLORESTA COMO FONTE DO DIREITO DAS MULHERES
}

\author{
HISTORY, CULTURE AND MEMORY: NISIA FLORESTA \\ LITERATURE AS WOMEN'S RIGHTS SOURCE
}

\begin{abstract}
${ }^{1}$ Alana Lima de Oliveira
\section{RESUMO}

Partindo do pressuposto de que a atividade de tradução é envolvida por um processo dinâmico, em constante movimento, capaz de mobilizar saberes, incompatível, portanto, com a ideia fixa, estável e universal da tradução literal, a qual foi pregada durante muitos anos pela teoria tradicional da tradução, foi possível concluir que a tradução cultural operada por Nísia Floresta ao texto fundante do feminismo no Brasil, embora não se trate de um texto jurídico e sim literário, contribui para a afirmação histórica dos direitos humanos das mulheres, assim como representa um efeito daquilo que se pode chamar de viagem cultural do direito.
\end{abstract}

Palavras-chave: História do Direito Das Mulheres; Feminismo; Tradução Cultural.

\begin{abstract}
Assuming that the translation practice is a dynamic process of constant movement that mobilizes knowledge, and is, therefore, incompatible with the fixed, stable, and universal idea of the literal translation(which was defended by the traditional theory for many years), we've reached the conclusion that the cultural translation accomplished by Nísia Floresta in the text that founded feminism in Brazil, despite being a literary and non-legal one, contributed decisively to the historical statement of women's human rights, and represents what we can call law's cultural voyage.
\end{abstract}

Keywords: Women Rights History; Feminism; Cultural Tradition.

\footnotetext{
${ }^{1}$ Mestra em Ciências Jurídicas pela Universidade Federal da Paraíba - PPGCJ/UFPB, Paraíba (Brasil). Professora do Departamento de Direito pela Universidade Estadual da Paraíba - UEPB, Paraíba (Brasil).

E-mail: alana.mdh@gmail.com
} 


\section{Notas Introdutórias}

Escrever sobre Nísia Floresta a partir do direito foi, sem dúvida, o maior desafio da presente pesquisa, haja vista que existem poucos trabalhados publicados no Brasil sobre a temática do feminismo numa perspectiva jurídico-política, porém, o interesse pela matéria e, principalmente, a necessidade de fomentar o debate acerca dessa autora, ultrapassou as maiores dificuldades.

Inicialmente, o nosso problema consistiu em investigar se o texto elaborado por Nísia Floresta em 1832, intitulado Direitos das Mulheres e Injustiça dos Homens como resultado à tradução do livro Vidications of the Rights Of Woman de Mary Woolstonecraft, podia ser classificado como uma tradução, já que a autora não realizou uma tradução literal, mas, uma tradução "livre", ou para outros, uma tradução cultural.

$\mathrm{Na}$ tentativa de dirimir esse problema, foi utilizado como referencial teórico os estudos da linguagem e da tradução, que afirmam que a língua assim como a prática de tradução são envolvidas por um processo dinâmico, em constante movimento, capaz de mobilizar saberes, incompatível, portanto, com a ideia fixa, estável e universal da tradução literal, a qual foi pregada durante muitos anos pela teoria tradicional da tradução.

Nesse sentido, o processo de tradução está para além da mera assimilação de significados, ou ainda, da simples transmissão de mensagens, o que resulta dizer que a atividade tradutória deixa de ser uma atividade de natureza exclusivamente linguística ou metalinguística, para ser uma atividade discursiva, ou seja, inscrita em um contexto marcado pelas diferenças ideológicas, políticas e culturais.

A tradução cultural operada por Nísia no texto que funda os primeiros ideais de uma consciência feminista no país, despertando a sociedade para a importância da participação feminina na vida pública, e ao mesmo tempo, reivindicando para a mulher a conquista de espaços nunca antes permitidos, aponta para o sentido de que é possível fazer da tradução uma forma de compreender o direito, ou até mesmo, de lutar por ele.

Traçadas essas linhas teóricas, a presente pesquisa objetiva fazer uma reflexão sobre a participação da mulher na escrita, sobretudo, na tradução enquanto "política feminista", aproveitando para discorrer sobre os aspectos linguísticos e discursivos da prática de tradução cultural, o que foi levado a cabo por meio de um estudo dedutivo bibliográfico, em que se buscou traçar um liame entre direito, literatura, tradução e feminismo. 
Em suma, trata-se de discutir o texto que se entende como precursor dos ideais feministas no país, na proposta de desvendar suas características principais, bem como, suas particularidades, e verificar como isso se refletiu no direito e na crítica literária, mormente, na tradução feminista contemporânea.

\section{A prática de tradução cultural como ato político e discursivo}

De acordo com a teoria tradicional da tradução, traduzir é reproduzir fielmente o texto de origem, logo, qualquer atividade que fuja a essa proposta não cabe dentro desse conceito. Para Dépêche (2000, p. 157), “a tradução, em sua acepção tradicional, remete a uma atividade impessoal e transparente que, supostamente, deveria transmitir com objetividade os sentidos estáveis das intenções do/a autor/a”.

Johnwill Costa Faria (2009, p. 19), estudioso da tradução, assevera que:

desde a Antigüidade, passando pela Idade Média e Renascimento, a idéia central sobre o tradutor e a tradução escrita está associada à imitação do texto original e ao respeito profundo ao seu autor. Durante os séculos XVII e XVIII, destacam-se duas tendências com características bem particulares: na Inglaterra, o período Augustan, e na França, a corrente das belles infidèles.

A crença de que a tradução consistia na transcrição fiel do texto original favorecia a criação de uma hierarquia entre o texto de partida e o tex to de chegada, sendo o original sempre superior ao texto traduzido.

Nesse sentido, durante o século XIX, a prática de tradução apareceu ideologicamente associada à prática colonialista dos grandes impérios, que impunham sua língua e sua cultura a terras alheias, sem considerar os valores destes lugares.

Citando Susan Bassnett em seu livro Estudos de tradução (2003), Johnwill Costa Faria pondera que:

um original era sempre visto como superior à sua cópia, precisamente do mesmo modo que o modelo do colonialismo se baseava na noção da apropriação de uma cultura inferior por uma cultura superior. Como tal, a tradução estava condenada a ocupar uma posição de inferioridade relativamente ao texto de partida do qual se considerava proveniente. (grifo nosso)

A menoridade do texto de chegada em relação ao texto de partida não só reafirmava o empoderamento do colonialismo, como consagrava a tradução à técnica de reprodução, que por 
sua vez, estava presa à ideia de fidelidade plena ao texto de origem, como se fosse possível tornar equivalentes os dois textos e, igualmente, as duas culturas.

Ao longo dos tempos, essa verdade passou a ser relativizada surgindo com isso a máxima italiana traduttori traditori, tradução é traição, ante à impossibilidade de tradução fiel e estável. Porém, a ideia de tradução como reprodução permaneceu viva até a primeira metade do século XX.

Com os estudos da linguagem e da tradução, verificou-se que a língua assim como a tradução era envolvida por um processo dinâmico, em constante movimento, incompatível, portanto, com a ideia fixa, estável e universal da tradução literal, a qual foi pregada pela teoria tradicional da tradução.

No dizer de Marie France Dépêche (2000, p. 158), "etimologicamente, traductio significa "fazer passar," remetendo à energia utilizada no ato de transferência pela atuação de um agente transformador”. Assim, à ideia de tradução liga-se a de transformação. Donde se deduz que é impossível a tarefa de tradução sem criação, interpretação e, por óbvio, transformação.

Ainda sobre o tema, adverte a autora que:

De fato, os termos "fonte" e "alvo" para designar os textos, as línguas e culturas de "partida/chegada" mal dissimulam que a operação é infinita em si e deste modo configura uma obra aberta a reprise, lingüística e historicamente. (DÉPÊCHE, 2000, p. 158)

Nessa perspectiva, entre o texto de partida e o texto de chegada existem vários elementos linguísticos e ideológicos que não podem estar fora do processo de tradução. A cultura de um povo/sociedade é um elemento importantíssimo no processo de tradução, de modo que, a tradução deixa de ser uma atividade de natureza exclusivamente linguística ou metalinguística, para ser uma atividade cultural, social e política.

Os textos são diferentes, não apenas porque foram escritos em línguas diferentes, mas, porque foram recepcionados em contextos culturais diferentes. A diferença que surge entre os textos não é só linguística, mas, sobretudo, cultural. Ainda que a proposta seja transcrever o texto original, quando se sai do texto de partida e se chega ao alvo desejado, vale dizer, a produção do texto de chegada, a recepção desse texto não se dá apenas pela nova língua, mas, pela história, a cultura, e a ideologia de determinado povo/sociedade. 
A tradução, portanto, passa a ser uma atividade discursiva, uma vez que não tem sua origem fundada apenas na língua, mas, no discurso. A concepção da tradução como atividade estável e transparente sucumbe diante da concepção de uma atividade dinâmica e opaca.

Como aduz Possenti (2001, p. 109) "não há discurso que não produza algum efeito", pois, "todo discurso, quer seja ele oral, quer seja escrito, causa sempre algum efeito, fazendo surgir novas práticas de linguagem e novos gestos de leitura". Assim, o sentido se constrói a partir do outro.

Quando um discurso é proferido, ele já nasce filiado a uma rede tecida por outros discursos, por isso é que se diz que nenhuma ciência pode ter a pretensão de ser totalmente independente e autônoma. Para Pêcheux (2008, p. 56), "todo discurso marca a possibilidade de uma desestruturação-reestruturação das redes e trajetos".

A metáfora da rede explanada pelo autor encaixa-se como uma luva para explicar o que é o discurso.

Uma rede, e pensemos numa rede mais simples, como a de pesca, é composta de fios, de nós e de furos. Os fios que se encontram e se sustentam nos nós são tão relevantes para o processo de fazer sentido, como os furos, por onde a falta, a falha se deixam escolar. Se não houvesse furos, estaríamos confrontados com a completude do dizer, não havendo espaço para novos e outros sentidos se formarem. A rede, como um sistema, é um todo organizado, mas não fechado, por que tem os furos, e não estável, por que os sentidos podem passar e chegar por essas brechas a cada momento. Diríamos que o discurso seria uma rede e como tal representaria o todo; só que esse todo comporta em si o não-todo, esse sistema abre lugar para o não sistêmico, o não representável. (INDURSKY; FERREIRA, 2005, p. 20)

Deste modo, podemos dizer que o sentido do discurso não é dado de imediato. Para Orlandi (1999, p. 21), "as relações de linguagem são relações de sujeitos e sentidos e seus efeitos são múltiplos e variados”. Daí a definição de discurso como efeito de sentidos entre locutores. O sentido é, pois, uma relação determinada do sujeito afetado pela língua e a história.

Assim sendo, o trabalho de tradução não se dá no vazio. No trajeto entre o texto de partida e o texto de chegada são considerados vários aspectos textuais e não textuais, dentre eles, a interdiscursividade. Traduzir não é apenas reproduzir o que está dito no texto original, mas, recriar o texto na língua de chegada, a partir dos elementos históricos e culturais daquele lugar, buscando revelar suas marcas discursivas, ainda que não estejam presentes no texto. 
De acordo com Orlandi (1999, p. 34), é possível “escutar o não-dito naquilo que é dito, como uma presença de uma ausência necessária", o que reafirma a ideia de que quando um discurso é proferido, ele já nasce filiado a uma rede tecida por outros discursos.

Logo, o processo de tradução também é acompanhado por um processo discursivo, que cria e recria o texto baseado na realidade social e histórica da língua de chegada. Nesse processo, a pessoa que faz a tradução assume o papel de mediadora, e como tal, faz da tradução uma atividade transformadora de significados.

A tradução aparece como uma atividade pessoal e subjetiva, à medida que o texto de chegada é escrito e inscrito em uma nova realidade social. Traduzir em/para outra língua significa enxergar o contexto, o intertexto, o qual não está materializado apenas na língua, mas, na cultura e ideologia.

No entendimento de Marie France Dépêche (2000, p. 157), o processo de tradução é envolvido por uma série de estratégias:

\begin{abstract}
Ao processo de "fazer passar" preside uma atitude ideológica, pois, repetidamente, requer escolhas: que texto(s) traduzir, para quem, por que, por quem e como? A tradução pressupõe estratégias tanto de (re)leitura, quanto de (re)escrita, uma (re)avaliação dos produtos de partida e chegada, bem como das táticas empregadas para essa passagem estreita. Ora, qualquer estratégia se inscreve em uma rede de poder, pois "[...] o texto é a encarnação de uma luta política conduzida [...] e interpretada, dentro de um quadro ideológico". Portanto, nenhum texto é puro ou inocente e a tradução, na sua qualidade de re-produtora, agrava e desdobra a violência das manipulações, "[...] modificando e deslocando o quadro ideológico do texto e os movimentos políticos subjacentes".
\end{abstract}

Assim, não há como prevalecer a ideia de que a tradução é impessoal, uma vez que o ato de traduzir já é precedido de escolhas que escapam à origem do texto. As bases ideológicas em que o novo texto está alicerçado têm a ver com a cultura e o pensamento político do texto de chegada.

Nessa linha de raciocínio, a tradução literal apresenta-se em oposição direta à tradução cultural. Nas palavras de José Pinheiro de Souza (1998, p. 51), "ao conceito de tradução literal está associada a idéia de tradução fiel, neutra, objetiva, e ao de tradução livre, a idéia de tradução infiel, parcial, subjetiva”.

A dinâmica pela qual é envolvida a atividade tradutória mobiliza o intercâmbio de saberes entre a língua de origem e a língua de chegada, o que significa dizer que as palavras e 
as coisas passam a fazer sentido quando começam a sofrer interferências externas que podem ser: a língua, a história e a cultura.

A discussão da história e a relação com o método arqueológico permeia a obra $\boldsymbol{A}$ arqueologia do saber (FOUCAULT, 2007), daí, surgem: a noção de acontecimento discursivo, o conceito de enunciação, o arquivo e o método arqueológico, o discurso, o sujeito e a história; além do agenciamento do saber e as regulações do poder.

Todos esses elementos da linguagem, portanto, contribuem para a assertiva de que os valores de uma sociedade recebem usos próprios na construção individual de seus próprios sentidos culturais, os quais podem variar no tempo e no espaço. Destarte, a atividade de tradução cultural se opera também dentro dessa dinâmica.

Para o professor Johnwill Costa Faria (2009, p. 54):

Se cada época produz seus próprios signos e estes se manifestam em modelos sociais e literários, constantemente alterados e renovados sob a perspectiva de uma cultura e uma língua, é natural concluir que tal fato se complica ainda mais quando se trata do caso das traduções, onde esta dinâmica se coloca entre duas culturas e duas línguas postas frente a frente, cada qual obedecendo a tendências variáveis, não coincidentes em sua totalidade e com estranhezas entre as duas partes em intercâmbio. Tais diferenças, ao serem mediadas pela tradução, exigem não só um ótimo conhecimento da língua e da cultura de partida, mas também, estratégias de tradução muito bem pensadas. (grifo nosso)

Isso significa que a prática da tradução assume variáveis que torna impossível sua análise sem esses elementos. Nesse sentido, o grande mote da tradução é ser abertura, diálogo, mestiçagem, descentralização, enfim, relação.

\section{A controvérsia sobre a ética na tradução nisiana}

Desde o momento que os escritos de Nísia Floresta foram redescobertos, aproximadamente no final da década de 1980, várias são as interpretações conferidas à sua produção textual mais famosa. Dentre elas, a de que a autora não teria feito uma tradução ao clássico de Mary Wollstonecraft, mas, uma reprodução do livro Woman not inferior to man (1739) de Sophie, pseudônimo de Mary Wortley Montagu (1689-1762), que, por sua vez, tinha se apropriado de partes do texto de François Poulain de La Barre (1673), intitulado De l'egalité des deux sexes. 
A afirmação partiu da pesquisadora Maria Lúcia Garcia Pallares-Burke (1996, p. 168) nos seguintes termos: "é [...] com um misto de constrangimento e entusiasmo que devo dizer que, de fato, jamais houve a aclamada tradução para o português da polêmica obra de Mary Wollstonecraft", e arrematou dizendo que o texto nisiano se tratava de um "plágio-tradução de outro plágio" (p. 178), certamente em referência às apropriações que Montagu fez do texto de François Poulain.

Embora a pesquisadora tenha ponderado em suas colocações, ao longo da obra, inclusive, no tocante à prática comum de plágio na literatura brasileira do século XVIII, sua interpretação ecoou como uma crítica ao trabalho daquela que é considerada a primeira feminista do Brasil.

Marcelle de Souza Castro (2007, p. 33) citando o estudo realizado por Lia Rolim sobre a prática de tradução em sua dissertação de mestrado, chama a atenção para o registro de que "em diferentes lugares e períodos históricos a tradução, ou a atividade de reescrita assim denominada por alguns, foi praticada sem qualquer preocupação de fidelidade para com a língua-fonte".

Destaca Rolim (2006, p. 74 apud Castro 2007) que:

na primeira metade do século XX, no Brasil nasceram os autores-tradutores, que dessacralizavam o original, colocando-se em posição de igualdade em relação ao autor estrangeiro, fazendo alterações significativas no texto, numa apropriação do original.

Portanto, a apropriação consistia em tomar como seu o texto de outro, o que autorizava o tradutor a interferir no texto, manipular, transformar, enfim, alterar a essência do original. Essa prática surgiu no Brasil com o modernismo e se tornou a marca da tradução do século XX.

Nesse sentido, eram comuns os empréstimos, as aliterações, o que era feito sem nenhuma referência ao texto fonte. Os escritores eram mais livres para escrever, ainda, que inspirados no pensamento teórico de outros. Nesse sentido, Nísia Floresta foi uma precursora dessa prática de tradução.

Tal como defendido por Duarte (2001), Nísia Floresta ao realizar seu trabalho de tradução se coloca no pensamento da escola do modernismo, portanto, à frente de seu tempo. A tradução que a autora realiza ultrapassa a instância do texto original. 
É a própria escritora que esclarece ao público leitor que Direitos das Mulheres $\boldsymbol{e}$ Injustiça dos Homens trata-se de uma "tradução livre" do tratado feminista de Mary Wollstonecraft, deixando claro que não consiste em uma reprodução fiel do texto original.

Para Constância Lima Duarte (2001, p. 157)

Ao realizar tais apropriações, Nísia Floresta está se inserindo na linhagem antropofágica da literatura brasileira (que tem Gregório e Sousândrade como representantes, bem antes de Oswald), ainda que com outras intenções, que não as meramente poéticas. Ela se apropria do texto europeu - é verdade , mas para superá-lo. Tanto é assim que o título de seu livro contém não apenas a idéia dos rights of woman, mas vai além e acrescenta "a injustiça dos homens". (grifo nosso)

Nesse sentido, as apropriações que a autora brasileira realiza no seu texto seriam plenamente legítimas, já que estariam dentro da lógica da "tradução livre". Em oposição à acusação de plágio levantada por Pallares-Burke (1996) sobre o texto nisiano, Constância Lima Duarte (2001, p. 159 - 160) adverte que

Nísia apropriou-se, sim, das idéias dominantes na Europa de seu tempo,
demonstrando com isto o quanto as conhecia, apesar de residir tão distante.
Mas seu gesto pode e deve ser lido como uma estratégia do dominado em usar
a linguagem do dominador, contra o próprio dominador. Antes de ser
considerada "plágio", tal atitude constitui-se num gesto de legítima
defesa; numa apropriação e numa desconstrução de escritos europeus
realizadas da perspectiva da periferia, visando à construção de um outro
texto. Ela se apropria dos discursos de Poulain de la Barre e de Catão
(manifestações distintas do discurso masculino europeu) para contestar o
mesmo discurso masculino, desta vez brasileiro. O gesto de Nísia teve, sim,
uma intencionalidade, e esta intencionalidade, já o dissemos, consistia em
denunciar as injustas relações de gênero existentes em seu tempo. (grifo
nosso)

Como já defendido, a intenção da autora ao se apropriar das ideias de fora não foi o de simplesmente copiar ou plagiar o texto estrangeiro, qualquer que consideremos Woolstonecraft, Sophie ou La Barre - mas, de transformá-lo em um produto nacional, ou seja, escrever a partir do caso brasileiro, em especial, da mulher brasileira.

A tradução libertadora, portanto, não estava associada à reprodução fiel do texto fonte. O tradutor não estava preso à ideia de fidelidade plena ao texto de partida, chegando muitas vezes a ignorar a essência do original, se colocando como o próprio autor da obra. Nesse giro, era frequente um escritor desenvolver seus textos, a partir dos escritos de outras obras, e sua atitude não era considerada uma ofensa, nem tampouco, era julgado de má fé ou antiético. 
A atividade de tradução nesse ponto de vista era transformadora. A questão da ética na tradução não estava relacionada à fidelidade ao texto fonte, mas, à proposta de ser diálogo, abertura, relação de troca de conhecimentos, interculturalidade etc.

Era necessário perceber o contexto histórico, político e sociocultural em que o original ia ser recepcionado, para daí, propor um trabalho de tradução. Nessa ótica, a prática de tradução não acontecia de forma estática, neutra, e sim, de forma dinâmica e interativa.

Tomando isso como fundamento, é incoerente pensar o texto de Nísia Floresta fora dessa perspectiva. Como já amplamente dissertado, o que Nísia Floresta praticou foi um trabalho de "tradução livre" e não literal. Isso muda tudo!

Consoante Constância Lima Duarte (2001, p. 160):

O fato de a autora ter indicado que se tratava de um texto "livremente traduzido" é um importante detalhe que não pode ser desprezado. É justamente nesta declaração de "liberdade" que estaria explicitado seu posicionamento diante dos que a antecederam. Ao publicar este Direitos das mulheres, ela se posiciona, portanto, de forma transgressora, na tensa relação do centro com a periferia, da margem com o Autor, sem sacralizar o texto europeu ou adotar uma atitude servil diante da autoridade autoral. Sem dúvida, teria sido bem diferente, e mais simples, se tivesse realizado apenas uma tradução literal e se colocado como porta-voz servil de discursos alheios. Ao contrário, sua atitude é sempre de independência perante a metrópole, não reconhecendo aí nem autoridade, nem propriedade. Mesmo que a atitude de Nísia Floresta seja vista como uma "pirataria" intelectual ainda assim é preciso relativizá-la como um gesto de defesa do oprimido. Em seu texto estaria a resposta da periferia ao centro produtor de discursos, portanto, construtor de identidades, e ainda mais: o grito do Ipiranga da mulher brasileira, frente à sociedade patriarcal. (grifo nosso)

Se a crítica literária aponta Nísia Floresta como plagiadora ou antiética, esse não é o ponto principal a ser investigado no seu texto. Para nós, o objeto de investigação consiste, na verdade, em perceber o que havia de novo no seu trabalho de tradução e o que a tornou uma escritora diferente dos outros escritores de sua época.

Independente das acusações que pesam contra essa escritora brasileira, o que podemos concluir é que o texto de Nísia Floresta representa um importante instrumento de combate ao discurso masculino, totalizante e universal da época, o que coloca a escritora como precursora de uma prática de tradução feminista conhecida na literatura como subversiva, e que só aparece como tal no século XX. 


\title{
4. Reflexões acerca da prática subversiva de Nísia Floresta à luz da tradução feminista contemporânea
}

A prática de tradução sempre foi associada à mulher. A raiz dessa comparação parte da concepção de que a produção dos originais era competência dos homens, enquanto que a tradução, por ser um exercício de mera reprodução, ficava ao encargo das mulheres.

A atividade de traduzir era colocada em segundo plano, o que gerava duas conclusões óbvias: a primeira, a de que a tradução é considerada uma atividade menor do que a produção do texto original; e a segunda, que assim como a tradução, a mulher ocupa uma posição de inferioridade frente ao homem.

Contra essa premissa ideológica, surgiram os ensaios de tradução feminista, com o fim de subverter a ordem dominante (masculina e falocêntrica) para dar visibilidade à mulher.

Aponta Marcelle de Sousa Castro (2007, p. 56) que:

\begin{abstract}
A partir dessa identidade entre tradução e mulher, as tradutoras feministas têm explorado a atividade tradutória como um importante elemento de sua luta político-ideológica. No momento em que a mulher rompe com os padrões convencionais de fidelidade e faz da tradução um espaço de criação de significados, ela está reivindicando também a valorização da mulher na sociedade, o reconhecimento da mulher para além do papel secundário que tradicionalmente ocupou. (grifo nosso)
\end{abstract}

Essa prática de tradução surge historicamente no Brasil, após a virada linguística de 1960, e ganha profundidade na década de 70, com escritoras feministas que passam a incorporar na sua agenda de debate a promoção da mulher. Essas escritoras faziam de seus textos expedientes através dos quais a mulher pudesse ser percebida como sujeito.

Para tanto, combatiam a linguagem patriarcal, e em seu lugar, utilizavam uma linguagem que dava voz e imagem às mulheres, no intuito de afastar o poder de dominação do homem sobre a mulher. A essência da tradução feminista está, portanto, em representar a mulher na língua, por meio de uma linguagem que nega a Ordem do Pai.

Segundo ainda a pesquisa de Marcelle de Sousa Castro (2007, p. 55)

Cada escritora feminista envolvida nesse projeto de revolução da linguagem falocêntrica (termo cunhado pelas feministas) parece ter utilizado estratégias diferentes de inovação e transformação da linguagem patriarcal, mas pelo menos dois pontos parecem permear o trabalho de todas elas: a) o reconhecimento da língua convencional como masculina e opressora da 
mulher - inclusive criaram o neologismo malestream, em lugar de mainstream, para indicar a presença predominante da perspectiva masculina nas línguas - e b) a constatação do emudecimento da mulher na linguagem, na história da literatura e nas ciências de modo geral. (grifo nosso)

Vê-se, com isso, que a linguagem tinha sexo e, para as feministas, ele era masculino, o que afastava a mulher também desse espaço, já que era um local de dominação do homem pelo homem. Portanto, a questão não estava só em identificar a linguagem como "falocêntrica", mas, as suas consequências em face da mulher.

As feministas passaram a reivindicar a construção de outro sexo para a língua(gem). E começaram pela diferença entre sexo e gênero.

O sexo é biológico: os seres humanos e a maioria dos seres vivos são fisiologicamente fêmea ou macho. $O$ gênero é socialmente construído: refere-se aos papéis sócio-sexuais, modos de se vestir, sistemas de valores e ordem simbólica aprendidos, impostos sobre os indivíduos pela cultura dominante de acordo com seu sexo de nascimento. [...] Contrariamente ao que o sistema social heterosexista nos teria feito crer, os papéis de gênero e comportamentos designados não são "naturais". (LOTBINËRE-HARWOOD, 1991, p.100)

Assim, sexo e gênero não estavam reduzidos a uma lógica binária, classificada em masculino versus feminino; homem versus mulher; macho versus fêmea, em que para um determinado sexo tem-se um determinado gênero.

O gênero é uma construção social e pode não identificar o sexo de nascimento da pessoa. Pensar as identidades de sexo e gênero sob esse prisma importa romper com paradigmas estabelecidos culturalmente acerca do que representa ser homem e ser mulher.

Nessa dinâmica de pensamento, a linguagem convencional é colocada em xeque e os elementos que a determinam passam a ser vistos sob outros aspectos que fogem à ideologia patriarcal.

O gênero e não o sexo passou a ser uma categoria importante na representação do universo masculino e feminino. Os papéis dos homens e das mulheres na sociedade deixaram de ser vistos como algo dado pela natureza, e passaram a ser analisados a partir de um contexto histórico e cultural.

Com os estudos de gênero, percebeu-se que era um contrassenso pregar a existência de uma língua natural. Na verdade, as línguas naturais só se justificariam em uma sociedade erigida pela dominação masculina. 
Por meio de uma nova linguagem era possível desnaturalizar a ideia de que a língua assim como a sociedade - era masculina e falocêntrica. Como instância de poder, a linguagem propagada pelas feministas serviu de luta político-ideológica em favor das mulheres. Portanto, o caráter subversivo da tradução feminista estava em colocar a mulher no centro do debate e proclamar a queda da ordem patriarcal na linguagem.

Embora essa prática só tenha surgido no Brasil na década de 1970, Nísia Floresta já manifestava em seus textos, mormente, em Direitos das Mulheres e Injustiça dos Homens de 1832, a condição da mulher e as injustiças sociais praticadas contra o "segundo sexo".

A forma como Nísia Floresta pensou e observou a mulher em pleno século XIX, fez de si, consoante aponta Marie France Dépêche (2000, p. 169-170), uma precursora da prática de tradução feminista contemporânea, sobretudo, da escola de tradução canadense:

Ao mesmo tempo independente em sua escolha de textos, mas também a eles ligada e ligando-os, Nísia Floresta abre o debate sobre a importância da intertextualidade feminista, que Susanne de Lotbinière-Harwood, hoje, assim descreve: 'Nossas re-belles e infiéis existem, portanto em, um movimento coletivo dialógico: por um lado beneficiam da contribuição criativa do intertexto. Por outro, contribuem à emergência de uma cultura no feminino, operando um aumento do vocabulário, do sentido, e da consciência".

No coração deste debate inscreve-se a questão do público-alvo (uma tradutora feminista visa exclusivamente as mulheres?) e da pertinência de confiar a tradução de uma obra feminista a uma mulher e sobretudo à uma tradutora feminista",.. .ou não. As escolhas, tanto de Nísia quanto das QuebecoCanadenses foi unânime: textos feministas, traduzidos por feministas para as mulheres ... feministas ou não.

Finalmente, seria necessário acrescentar a prática da sobre-tradução empregada por Nísia, que será analisada, comentada, criticada em nosso século, da qual porém, as tradutoras do Quebec usarão com frequiência. Tratase de sobre-elementos tirados da polissemia do significante, que asseguram a sobre-tradução, (supplementing diriam as anglófonas); não como pretendia Benjamin, uma multiplicidade levando à reine Sprache, a língua pura da escatologia das línguas, mas o acréscimo necessário ao ato tradutor da "[...] tradutora feminista, consciente de seu papel político como mediadora. [...]”. Esta prática aparece em toda discussão, com seus acréscimos voluntários, como um enriquecimento do texto, que coloca Nísia entre as precursoras das estratégias feministas do século XX em matéria de tradução. (grifos nossos)

Deste modo, pode-se asseverar que por trás da tradução de Nísia Floresta havia um nítido propósito de romper com a ordem dominante, o que confirma o lado subversivo da obra, fazendo de Nísia ora traidora, ora tradutora do texto que se imagina como precursor da ideologia feminista. 
Ao recriar a obra Vindications of the Rights of Woman de Mary Wollstonecraft no contexto brasileiro, Nísia tira a mulher do isolamento doméstico e a coloca no centro do debate, a fim de desvendar seu papel, assim como, suas inscrições históricas, políticas e culturais na sociedade do século XIX.

Portanto, o texto de Nísia Floresta desperta a sociedade para a necessidade de perceber a mulher fora do espaço privado, sinalizando que é possível uma vida com dignidade, sem analfabetismo, sem submissão à ordem masculina, o que segundo seu manifesto só ocorreria por meio da educação.

Conclui-se, assim, que a obra de Nísia Floresta coopera (ainda que tardiamente) para a mudança de pensamento da elite brasileira no final do século XIX, o que demonstra a relevância teórica de Direitos das Mulheres e Injustiça dos Homens para as futuras gerações, tanto no campo do direito quanto da literatura.

\section{Notas Conclusivas}

A primeira conclusão que se pode apontar, após o estudo em debate, é que a presente pesquisa propiciou um novo olhar sobre a história do direito das mulheres no Brasil, mormente, em seu nascedouro.

A pesquisa aqui desenvolvida procurou contar a história do direito das mulheres, a partir do projeto de tradução cultural de Nísia Floresta ao tratado feminista de Mary Woolstonecraft, de 1792, intitulado Vindication of the Rights of Woman, na proposta de perceber a história do direito das mulheres diferente da sua concepção tradicional e legal, ou seja, compreender a história do direito das mulheres enquanto ideologia e sistema de pensamento, e não como a história das leis e dos institutos jurídicos criados em favor da mulher.

Não se quer dizer com isso que seja dispensável estudar a história dos institutos jurídicos, ao contrário, é de suma importância estudar o direito das mulheres com ênfase na legislação, afinal, essa também foi uma luta travada pelas mulheres, porém, essa não foi a intenção da presente pesquisa. O grande objetivo, que acreditamos ter sido alcançado, era construir um trabalho que dialogasse com outras áreas do conhecimento, e até mesmo com fontes não formais do direito, como a literatura e a tradução, o que à princípio pareceu assustador, mas, logo que a pesquisa tomou corpo, traduziu-se em um grande prazer.

Estudar a história de Nísia Floresta como feminista e idealizadora dos primeiros sentimentos de justiça, dignidade, educação e cidadania feminina foi o mesmo que estudar a 
história de uma personagem real e antiga do direito, que por meio de sua literatura, mais especificamente, da obra Direitos das Mulheres e Injustiça dos Homens, contribui de forma decisiva para a afirmação histórica dos direitos humanos das mulheres.

De acordo com Constância Lima Duarte (2008), há uma unanimidade entre os autores em afirmar que o escrito de Nísia Floresta constitui o texto fundante de uma ideologia feminista no país, já que nunca houve na história um texto elaborado por alguém como Nísia, com o objetivo de clamar pela importância da mulher na sociedade, de reivindicar o acesso ao espaço público, de lutar pelo direito à educação, ao conhecimento, à oportunidade de trabalho fora do confinamento doméstico, enfim, pela igualdade de direitos entre os sexos.

Por outro lado, relacionar os estudos feministas da linguagem e da tradução com o direito ensejou desafios teóricos maiores do que o almejado inicialmente, pois, viu-se a necessidade de um melhor aprofundamento nas teorias da tradução, sobretudo, no que se refere à tradução cultural, uma vez que o estudo tradicional da tradução não era suficiente para os possíveis resultados pretendidos. Isto porque a hipótese levantada na pesquisa constituía em desvendar se o texto Direitos das Mulheres e Injustiça dos Homens podia ser classificado como uma tradução ao clássico de Mary Woolstonecraft.

Por meio dos estudos culturais da tradução, mormente, a crítica de Constância Lima Duarte (2001) a conclusão que se chegou é que o trabalho empreendido por Nísia ao texto de Wollstonecraft configura-se sim em uma tradução. Obviamente que não se trata da tradução literal, tão convencionalmente conhecida, mas, de uma tradução cultural.

A tradução praticada por Nísia Floresta foi feita às avessas da tradução literal, pois considerou o contexto brasileiro, a cultura local, para discutir e pensar a situação das mulheres. Diante do abismo cultural, social, político e econômico que havia entre a Europa e o Brasil, a forma que Nísia encontrou de tornar reais as ideias e intenções de Mary Woolstonecraft acerca dos direitos das mulheres foi por meio da tradução cultural.

Outrossim, foi possível concluir que a atividade de tradução realizada por Nísia Floresta faz parte de um fenômeno mais abrangente do processo de circulação e recepção de ideias, pois, ao propor a tradução do livro que é considerado o principal tratado feminista da época, Nísia não se limitou em transcrever o texto original para o português, mas acima de tudo, em traduzir uma ideologia, em transferir ideias jurídicas acerca do feminismo e do direito das mulheres de um contexto cultural para outro.

Essa foi a sua grande invenção! 


\section{REFERÊNCIAS}

CASTRO, Marcelle de Souza. Tradução, ética e subversão: desafios práticos e teóricos. Dissertação (Mestrado em Letras) - Pontifícia Universidade Católica do Rio de Janeiro, Rio de Janeiro, 2007.

DÉPÊCHE, Marie-France. A Tradução Feminista: Teorias e Práticas Subversivas. Nísia Floresta e a Escola de Tradução Canadense. Revista Textos de História, Vol. 8, n. 1/2. p. 157188. Universidade de Brasília - Unb. 2000. Disponível em: http://periodicos.unb.br/index.php/textos/article/viewFile/5908/4885. Acessado em: 20 jul. 2014.

DUARTE, Constância Lima. Nísia Floresta: vida e obra. $2^{\mathrm{a}}$ ed. Natal: Editora Universitária (UFRN), 2008.

Constância Lima. Nísia Floresta e Mary Woolstonecraft: diálogo ou apropriação? Revista de Literatura Brasileira - O eixo e a roda, vol.7. p. 153-161. UFMG. 2001.

FARIA, Johnwill Costa. Of mice and men, de John Steinbeck: a oralidade na literatura como problema de tradução. Dissertação (Mestrado em Letras) - Universidade de Brasília. Departamento de Línguas Estrangeiras e Tradução. Brasília, 2009.

FLORESTA, Nísia. Direitos das Mulheres e Injustiça dos Homens. Ed. atualizada com Introdução, Notas e Posfácio de Constância Lima Duarte. São Paulo: Cortez editora, 1989.

INDURSKY, Freda. FERREIRA, Maria Cristina. Michel Pêcheux e a Análise do Discurso: uma relação de nunca acabar. São Carlos-SP: Claraluz, 2005.

LOTBINIÈRE-HARWOOD, Susanne de. Re-belle et infidèle/The body bilingual. 1. ed. Montreal: Les éditions du remue-ménage; Toronto: Women's Press, 1991.

ORLANDI, Eni Puccinelli. Análise de Discurso: princípios e procedimentos. Campinas: Pontes, 1999.

PALLARES-BURKE, Maria Lúcia Garcia. Nísia Floresta. O carapuceiro e outros ensaios de tradução cultural. São Paulo: Hucitec, 1996.

PÊCHEUX, Michel. O Discurso: Estrutura ou Acontecimento. Trad. Eni Puccinelli Orlandi. $5^{a}$ ed. Campinas, SP: Pontes, 2008.

POSSENTI, Sírio. Discurso, estilo e subjetividade. $2^{\text {a }}$ ed. São Paulo: Martins Fontes, 2001.

SOUZA, José Pinheiro de. Teorias da Tradução: uma visão integrada. Revista de Letras. $n^{\circ}$ 20. vol 1/2. p. 51-67. Universidade Federal do Ceará - UFC. Jan/dez. 1998. Disponível em: http://www.revistadeletras.ufc.br/rl20Art09.pdf. Acessado em: 17 Jul. 2014

WOLLSTONECRAFT, Mary. Reivindicação dos direitos da mulher. Trad. Ivania Pocinho Motta. $1^{\text {a }}$ Ed. São Paulo: Boitempo, 2016. 